\title{
Public home care professionals' experiences of being involved in food distribution to home-living elderly people in Sweden - a qualitative study with an action research approach
}

\author{
Zada Pajalic $^{1}$, Lena Persson ${ }^{1}$, Albert Westergren ${ }^{1}$, Kirsti Skovdahl $^{2}$ \\ 1. School of Health and Society, Kristianstad University, Kristianstad, Sweden. 2. School of Medical and Health Sciences, \\ Örebro University, Örebro, Sweden. \\ Correspondence: Zada Pajalic. Address: Högskolan Kristianstad, 29188 Kristianstad, Sweden. E-mail: \\ zada.pajalic@hkr.se
}

Received: November 22, 2011 Accepted: January 11, $2012 \quad$ Published: May 1, 2012

DOI : 10.5430/jnep.v2n2p41 URL: http://dx.doi.org/10.5430/jnep.v2n2p41

\section{Abstract}

Background: Research focusing on Food Distribution (FD) from various professionals' and organisational perspectives are lacking. The aim of this study was therefore to explore various professionals' experiences of involvement in FD in order to get comprehensive understanding of the organisation, responsibilities and roles.

Methods: This qualitative study is a part of a larger project with an action research approach focusing on FD in the municipal home service and care for home-living elderly persons in a municipality in southern Sweden. The data was collected through participatory observations ( $\mathrm{n}=90$ occasions and in total 480 hours), repeated focus group interviews $(\mathrm{n}=$ 4) with different professionals $(n=10)$ involved in the FD process and one individual interview. The material was analysed by qualitative manifest and latent content analysis.

Results: The study indicates that Food Distribution is a fragmentary intervention where a comprehensive perspective and clear roles of responsibility are lacking. The FD organisation seemed to be strictly divided and limited by constraints regarding time and money. The fragmented organisation led partly to staff only taking responsibility for their part of the chain and no one having the full picture of and responsibility for the FD process, but also to some professionals taking more responsibility than they were supposed to.

Conclusions: The aim of the study was met by using an action research approach. The study was however limited by that no home help officers were represented. The FD appeared as an extremely complex chain of different but connected activities. It is not merely the distribution of a product, i.e. the meal box. The fragmentation of FD means that staff only takes responsibility for their part of the chain, and that no one has the full picture of or responsibility for the FD process. Consequently, there is a need for an outline of responsibilities. The findings have implications for nursing, gerontology, and in the care for the elderly.

\section{Key words}

Action research, Elderly people, Food distribution, Focus group, Organisational perspective 


\section{Introduction}

Research focusing on Food Distribution (FD), comparable to the international concept of "meals on wheels", is lacking from several professional and organisational perspectives. Little is known about how FD is experienced by various professionals, or about the FD organisation and the involved professionals' responsibilities ${ }^{[1-3]}$. Through such knowledge it might be possible to optimise FD in order to avoid negative consequences for its recipients, such as improper nutrition and social limitations.

In Sweden, the purpose of FD is to distribute complete meals to elderly people and persons with health related impairments who have difficulties making food by themselves and cannot meet this need in any other way. The municipalities have the overall responsibility for FD, which is regulated by two laws, the Social Services Act and the Health and Medical Services Act ${ }^{[4]}$. Neither of these laws regulates in detail how FD should be organised, which gives the possibility for each municipality to organise FD based on its own circumstances. The FD is a statutory right financed by public funds and is supposed to be accessable on the principle of needs ${ }^{[4]}$.

Although international literature indicates that there are different ways of organising the FD, it has the same purpose: to give care and service to home-living elderly people with special focus on securing their food intake.

Only when elderly people are not able to make food by themselves and their needs cannot be met in any other way, does it become a public, i.e. municipal, obligation ${ }^{[5,6]}$. Many elderly persons are disabled and dependent on others for acquiring and preparing food. Approximately 200 out of a total of 290 municipalities in Sweden produce food for FD, most often in the form of lunch, either distributed daily as a hot meal (60 degrees) or weekly as a cold meal ${ }^{[7]}$. The number of elderly persons in Sweden receiving food by FD is estimated to 60,000, and the population prognosis shows that the need for FD will increase ${ }^{[8]}$.

FD in Sweden requires a complex organisation involving different professionals and decision making at various levels, such as: the decision-makers (politicians, committees and civil servants in the administration, such as public home officers, diet managers, team managers); the food producers (often the municipally run production kitchen and kitchen professionals), the food transport (assistant nurse) and caring professionals (assistant nurses) ${ }^{[9]}$. The main rule regarding fees is that they are lower for those with poorer ability to pay ${ }^{[4]}$. In that way, the organisation of FD in Sweden differs from that in other welfare countries such as the US, Canada, Australia, Holland, Ireland, Japan and other countries where FD is organised by either private companies or voluntary organizations ${ }^{[10-15]}$. Even if the FD systems differ, the FD is a concrete welfare intervention for home-living elderly people.

It is important to have knowledge about the professionals' views of FD in order to be able to implement successful interventions aiming at improving the service and care connected with FD. The professionals are experts on what goes on in everyday practice, and this knowledge is beneficial for the development of practice ${ }^{[16]}$. Professional knowledge, quality improvement and an understanding of the impact of interprofessional teamwork and learning are of vital importance for improved outcomes in service and care ${ }^{[17]}$. However, a literature search indicates that existing research focusing on FD from various professionals' perspective is missing. Furthermore, the FD system in particular and how it is situated has not been described.

Research has shown that the consequences of improper food intake are identical, irrespective of geographical context ${ }^{[18-20]}$. The organisation in each context, its benefits and limitations, is important for building knowledge that can contribute to developing the FD context irrespective of geographical borders. By understanding the organisation of FD, and the involved professionals' responsibilities and experiences, it might be possible to improve FD in order to give optimal service to the home-living elderly persons. A literature search indicates that this study is a necessary contribution to the field. It provides new information about the little-researched issue of various professionals' experiences of 
involvement in the food distribution process, which gives a more comprehensive understanding of the organisation, responsibilities and roles.

The aim of this study was to explore various professionals' experiences of involvement in the food distribution process in order to get a comprehensive understanding of the organisation, responsibilities and roles.

\section{Method}

\subsection{Design}

The study is a part of larger research project with an action research (AR) approach ${ }^{[21]}$, focusing on FD in municipal service and care for elderly persons in southern Sweden. This study has a qualitative design inspired by Action Research $(\mathrm{AR})^{[21-23]}$.

\subsection{Context and participants}

The study was conducted in one of three geographical areas in an average-sized municipality of approximately 75,000 inhabitants in southern Sweden. Due to the context of the FD, it was necessary to include all different professionals that were involved in the FD process ${ }^{[21]}$. All participants were democratically involved by being offered to share their experiences and everyday knowledge. The manager of all kitchen professionals was chosen as a gatekeeper for facilitating contact with the different professional groups involved in the FD process. An initial meeting between the professionals was organised and the study was presented to these people. The meeting was attended by eleven persons, in addition to the first author. Everybody present at the meeting was asked to participate in the study, and to give their written consent. After the meeting, four registered nurses, three assistant nurses, three kitchen professionals and their manager, i.e. the gatekeeper, agreed to participate in the study. In addition, one taxi driver was included.

\subsection{Data collection}

The data collection included repeated focus group sessions $(n=4)^{[24]}$, participatory observations $(n=90$ occasions and in total 480 hours ) and one separate individual interview ${ }^{[25]}$. The observations were conducted with each of the participants in the focus group. One taxi driver, who was part of an externally purchased service, participated in one semi-structured individual interview and one observation. These different sources of data were used to gain a broader understanding of FD, all in agreement with the AR approach ${ }^{[26]}$.

The first author and the participants agreed to start with one focus group session, and between each following focus group session the first author was to be a "guest" at each participant's work place. The participatory observations were performed with for instance the cook in the kitchen for general food; the cook for special food, such as diabetic food, gluten free or fat free food; catering assistance, packaging, transportation, delivery and meal assistance in the elderly people's houses. Field notes were taken and used to describe and understand the study context.

The first focus group session started with a presentation of the participants and their own role in FD. The degree of involvement from participants in the research process was discussed, and it was decided that the researcher, i.e. the first author, should be responsible for the facilitation of focus group sessions, data gathering, transcriptions and analysis ${ }^{\text {[27] }}$. The following questions were focused on: the participants' experiences of being involved in FD and their responsibilities and roles. The researcher was the facilitator, encouraging the participants to reflect on the question. The following three focus group sessions started with a short summary of the previous session and then continued with questions based on the observations the first author had made since the previous session. During the last session, preliminary findings from the data collections were discussed together with the participants in order to ensure recognition and agreement with the findings ${ }^{[21]}$. Each focus group session lasted about 60 minutes. The focus group interviews were tape-recorded. During the 
interviews, interactions between participants were observed. These observations were taken into account in the analysis process. The interview ${ }^{[25]}$ with the taxi driver lasted about 30 minutes and was also tape-recorded. All interviews were transcribed verbatim.

\subsection{Analysis process}

The verbatim interview transcripts were analysed using manifest and latent content analysis ${ }^{[28]}$. The transcripts were read by the authors so that they would gain a sense of the whole picture and be able to express ideas for the further analysis with the study aim as a basis. Meaning units were identified, condensed and labeled with a code that described the content. A manifest analysis was used to describe the obvious and visible in the text. The codes were reflected upon and sorted into sub-categories that in next step were sorted into categories. In total, three categories were identified: "Views on the individual's role in FD", "Views on the elderly people and their food habits" and "Developmental areas of FD". As a further step, the content was reflected upon and discussed in the research group. A latent analysis was performed in order to grasp the underlying meaning in the text ${ }^{[28]}$. Questions about what the text was talking about and what this meant were "addressed to the text" in order to reveal the deeper structural meaning ${ }^{[29]}$. The latent analysis consisted of dialectical movements between the whole and the parts, between understanding and explanation and between explanation and comprehension. A main theme was identified: "Food distribution as a fragmentary intervention, i.e. without coherent links". All steps in the analysis were critically discussed in the research group. The authors discussed the findings in relation to the research question and agreed concerning the final description of the categories and the interpretation of the theme.

\subsection{Ethical considerations}

The study was performed in accordance with the Helsinki Declaration ${ }^{[30]}$, and has been examined by the regional ethical review board (LU09/365). All participants gave their informed consent to participate in the study after having been presented with detailed information about the study and their own participation; they were informed that they had the right to end their participation at any time without it having any consequences for them.

\section{Results}

\subsection{Description of the explicit FD context}

The process of the FD directly involved several different professionals, e.g. kitchen professionals (diet manager, cooks, catering assistants) and their manager, taxi professionals, home help officers, assistant nurses and indirectly district nurses. All professionals except the taxi driver were employed by the municipality. The home help officers were responsible for making an assessment of each elderly person's need of FD. The manager of all kitchen professionals was responsible for the quality of food as a product and for the kitchen professionals. The kitchen professionals were responsible for food production, packaging, food quality control and distribution follow-ups. The production capacity in this kitchen was about 600 portions a day, of which 130 to 150 were prepared for FD. Assistant nurses were responsible for the transportation of food and assistance during meal times, the taxi drivers were responsible only for transportation and for handing over the food personally to its recipients, i.e. the elderly person. The taxi drivers distributed food to areas where the assistant nurses did not have access to cars. The taxi driver reported to the kitchen professionals if the elderly people did not open the door to receive their food. The routine in those cases was that the kitchen professionals phoned the elderly person to check what had happened. If the person did not answer when they phoned, the kitchen professionals were required to contact the assistant nurses, or the elderly person's relatives, to prompt them to check on the person. The district nurses were responsible for nutrition and screening of related improper nutrition consequences as part of the nursing process. They had geographically based responsibility, i.e. for all recipients of social and care services in their own homes. Their work was stated by the "threshold" principle, which means providing home care to people who cannot leave their homes and visit local care centres. Visiting the elderly in their homes could be initiated by physicians, by the hospital (if the elderly people 
are there as patients and they need to be followed up with home care), by the elderly people themselves, their relatives, public home officers and assistant nurses. The FD in itself was not a reason to involve the district nurses, since it is regarded as a social intervention rather than a care intervention. Thus, the regulations concerning the distribution of hot food had two aims: one was to deliver hot food of good quality, and the other was to ascertain that the elderly people were well. The home-living elderly people who receive FD order their food monthly and can choose between two dishes including dessert. They pay only 10 per cent of the actual cost and there is a limit to how much they have to pay, which in this municipality amounts to 1600 Swedish kronor per year (about 170 US dollars). For the elderly people who do not have any possibility to pay, FD free and financed by taxes.

\subsection{Food distribution as a fragmentary intervention, i.e. without coherent links}

The main theme that characterised the various professionals' experiences and reflections was: "Food distribution is a fragmentary intervention, i.e. without coherent links”. A general complaint is that there is no comprehensive view of the entire process and objective, on which the various professional groups can collaborate while doing their specific work in the FD process according to clearly stipulated protocols.

We believe that there's a problem with only delivering the food and not being involved in other aspects of the food distribution process [...] we would like to see an overall assessment of the process.

The absence of such a coherent and comprehensive perspective resulted in frustration with indistinct and vague divisions of responsibility regarding the FD process. Furthermore, the results show that in many cases, the only professional groups that had immediate contact with the elderly persons on a daily basis were the taxi drivers or assistant nurses - who had the least education in nursing and health care. Those with the most education, the district nurses, were less involved with the elderly persons. This led to frustration, since it was difficult for district nurses to gain a comprehensive view of the FD. Findings from the interviews also showed that there were no clear, or sufficient, follow-ups of what happened when the meal box was delivered to the elderly person. They also said that there was no subsequent evaluation of to what degree the food was adjusted to the elderly persons' wishes and needs, or whether they actually ate the food. They stated that it was important to decide whether FD was to be regarded as a medical measure or as a social intervention. The latter - being merely a social intervention - did not require the involvement of district nurses. Moreover, the results showed that the kitchen professionals and their manager were the only - albeit informal - coordinating body, or link, between all the professional groups involved. However, they did not have a formal mandate, and this kind of coordination was not included in their work duties. The above latent interpretation was built up from three categories that are described in detail in the following text.

\subsection{Views of the individual's role in the food distribution}

The focus groups revealed that the involvement in and the purpose of FD was described in various ways depending on the participant's professional role and level of responsibility.

The district nurses claimed to be involved in the FD merely indirectly in the sense that they were informed about the elderly persons' food intake through the reports of the assistant nurses. The district nurses said that their contact with the elderly persons was usually initiated in connection with discharge from the hospital or prescribed by a district physician. Only in a few circumstances were they contacted by the elderly persons themselves. The district nurses were dependent on the assistant nurses, since they were the ones who actually saw the elderly persons and worked closely with them.

...I find it hard to know what the elderly people eat, and I trust that the assistant nurses would inform me...

The district nurses described their responsibility as educating and supporting the assistant nurses, the elderly persons and their relatives in how to follow up results of food intake. This could for instance be observations of whether the food in the 
meal boxes was eaten or not, or weight checks. The district nurses, however, claimed to lack routines for following up on results of food intake by measures such as Body Mass Index or weight checks. This was common in nursing homes, but not in the same way in private homes. They described home visits as opportunities to get their own view of the elderly person's eating habits.

Sometimes it's good to accompany the elderly people to their fridge, and when they open it, and you get to see what's in there, you're able to assess the cooking and catering situation.

The district nurses also emphasised the fact that they had the mandate to influence other professionals in prescribing further nursing assistance for meals.

Unlike the district nurses, the assistant nurses described their close work with the elderly persons. They described how they were able to offer support in everyday situations by reminding the elderly persons to buy (more) fruit and vegetables. But their main tasks were to provide the elderly person with practical help by opening the lunch box and putting the food on a plate. The assistant nurses described how they provided all practical help in dialogue and in agreement with the elderly persons. Sometimes they had to follow specific written instructions from relatives, however, e.g. how to handle meals, snacks and shopping. The assistant nurses felt that they had no way of influencing their work situation, since their time at the elderly person's home was very limited. They often only had five minutes to perform necessary food-related tasks. The assistant nurses themselves said that they would want to be able to spend more time with the elderly persons during mealtimes, as company. They thought that their presence could be a way to influence the elderly persons' appetite and eating habits in a positive way.

To just sit there beside the elderly persons can be a bit stressful, since they know we're on a schedule and need to be off to the next person. I think that would be different if we sat down and ate together with them.

The kitchen professionals said that they were responsible for the quality, production and packaging of the food and for the coordination of its distribution. The most important task was to deliver the food on time. Evaluating the FD from the elderly persons' and their relatives' perspective was also part of their responsibility. This was expressed in terms such as:

...in our surveys, we have noticed that some believe the food to be too spicy and that some do not think it is spicy enough! When I look at the responses in the evaluations, I realize what an impossible work situation we have. It is impossible to make everybody happy and content. The flavour of food is so individual and personal...

The taxi driver described his and other taxi drivers' role in the FD process as a link between the kitchen and the elderly persons. He claimed to follow the routines, and said that he would report to the kitchen professionals if something was wrong. The taxi driver showed a human side when he said that he cared about the elderly persons, even if it was not an obligation on his part, since he was in contact with them on a daily basis.

\subsection{Views on the elderly people and their food habits}

Through various situations and encounters with the elderly people, different professions had different perceptions of elderly persons' eating patterns. The experience of the district nurses was that the elderly persons did not want changes in their lifestyle or habits. They also thought that the elderly persons had restricted funds and financial capacity, as they had observed many situations where the elderly persons seemed to have to choose between paying for medicine and paying for food. The district nurse also observed that a majority of the elderly persons had impaired physical abilities, which affected their eating situation. They pointed out that many elderly people need assistance during the meals.

Sometimes the elderly persons are assisted in getting their food ready to eat, but then it turns out that they may not even be able to eat it due to lack of energy. 
The assistant nurses experienced that some elderly persons were actively involved in choosing their food. Nonetheless, they noticed that the elderly people often chose the same kind of food and excluded fruit and vegetables because those foods seemed too expensive. Contrary to their wishes to eat together with the elderly people, they observed that many of the elderly persons preferred to eat alone even if they needed assistance during the meals.

The kitchen professionals felt that the elderly persons had the possibility to influence their own meals, and claimed that they asked for the elderly persons' points of view in order to be able to give the best service possible. They had noticed that some elderly persons took a more active interest in the evaluations and were more likely to answer them. The kitchen professionals believed that this was a result of their actually making changes to the food based on suggestions they received from the elderly persons in the evaluations. The kitchen professionals believed, in general, that the elderly persons were not getting adequate nourishment, but that this was primarily due to a lack of knowledge among the elderly persons about their nutritional needs. In the experience of the taxi driver, the elderly persons wanted to get their food at the same time every day and from the same person.

\subsection{Reasoning about the food distribution}

The district nurses found FD difficult to coordinate and thought that it was an organisational weakness to involve professionals outside of their own organisation, e.g. taxi drivers. They found it unfortunate, since the taxi driver does not have any obligations to report deviations and therefore, food should be delivered by assistant nurses. They found it hard to accept external professionals without any education or training in nursing or health care. They pointed out that assistant nurses are also responsible for observing the elderly persons' food intake and reporting deviations to them. Above all, the district nurses thought that it was of the utmost importance that the quality of the taxi professional's service should also be evaluated and reported. According to the assistant nurses, FD is strictly regulated by laws, rules and routines. They felt that elderly persons' difficulties in ordering food are neglected in the needs assessment, i.e. they needed help to fill out the orders correctly and send them to the kitchen on time. According to the kitchen professionals, FD is a continuous process that is constantly being developed. The logistics work well and their product, i.e. the food, is varied and nutritious. They pointed out that they are continuously struggling with the risk that things might go wrong, e.g. that the wrong dish is sent or that someone's food delivery is forgotten about.

\section{Discussion}

\subsection{Methodological considerations}

Based on the AR approach, a "bottom-up” perspective was used. However, the professionals' work situation and lack of time made it impossible for them to continue their involvement in the problem solving phase, intervention and evaluation. Furthermore, the intention was to recruit strategic participants from every profession involved in FD. The home help officers were, however, not represented in spite of several oral and written invitations to participation in the study. The research process lasted for about one year, and confidence, trust, engagement and collaboration between researcher and participants could therefore be established. The focus group evaluated their participation in the following way: firstly, they had learned what it means to do research in practice and through this, their way of observing their practice had changed from just looking to actually seeing what is happening. Secondly, they realised that FD had been put on the agenda. Their evaluation of participation in the present study showed that they created a forum of their own for the development of knowledge through evidence and reflection ${ }^{[21]}$.

The researcher summarised and gave feedback to the participants at the end of each focus group session, and the researcher thereby ensured that the participants recognised and agreed with the findings. Additionally, all of the authors were involved in the analysis. Dependability was assured by the fact that the same researcher, the first author, facilitated the focus group sessions, performed participant observations and carried out the individual interview and the transcriptions. 


\subsection{Discussion of findings}

This study aimed to explore various professionals' experiences of involvement in the food distribution process in order to get a comprehensive understanding of its organisation, responsibilities and roles. FD was described as a fragmentary intervention lacking a comprehensive perspective and clear responsibility. The fragmentation became clear when the participants described their involvement in comparing the level of their competence and their area of responsibility. The district nurse's competence was not used to prevent possible consequences of improper food intake. Screening of nutritional status for home-living elderly people did not exist and it seemed to be presented to the elderly people as their own responsibility. Further, it was shown that the kitchen personnel and taxi drivers took informal responsibility to compensate these routines. In addition, it seemed like those most closely involved in FD were unaware of the larger policies, budget processes and other issues that influence the FD process.

That food-related tasks are delegated to professionals who are less qualified in nursing could be an indication that those tasks are of less importance and have amateur status ${ }^{[31]}$. Not involving professions with competence in nursing or health care is associated with economic reasoning, since less skills and education equals lower costs ${ }^{[32]}$.

The present study shows that the assistant nurses did not have time to spend with the elderly people during the meals. The lack of time limited their professional independence, which is a precondition for giving social support and following up on the elderly people's needs properly. During the last few decades, public care, including public home care in welfare countries as well as in Sweden, has undergone major organisational changes due to limited financial resources. As a consequence of these major organisational changes, the new method of New Public Management (NPM) was introduced to guide the work in practice. NPM focused on introducing an organisational model inspired by marketing into the public home care sector. The NPM model is based on organising work in a standardised, detailed and top-down way where tasks are decided in advance by one group of professionals and performed by another group of professionals ${ }^{[33]}$.

There is clearly a tension between the needs of administrators, particularly due to budgets, to routinise tasks into component parts. This leads to a Tayloristic way of thinking and to a manufacturing (time and motion) approach to care provision. The opposite is a holistic approach to care ${ }^{[34]}$. Thus, a question that arises, from the results of this study, is whether the purpose of home care is to provide standardised units of intervention, or to care for the actual needs of the frail elderly. What elderly people, an otherwise isolated population, need are customised meals, someone to observe their situation and get to know them as a person, and someone to provide human contact ${ }^{[35]}$. While it is not often reported in the literature, qualitative and anecdotal data indicate that simple human contact and kindness can have a significant and beneficial effect on mood and overall health, perhaps more than some standardised interventions ${ }^{[36-38]}$.

The dichotomy between the FD as a health care or social intervention is complicated by different perceptions across the political and policy spectrum about the relative social worth of elderly people and whether supportive services should be seen as a part of health care and, thus, should be seen as a legitimate response to a health care need ${ }^{[4,39]}$. What policy makers may fail to grasp is that elderly people have legitimate medical conditions ${ }^{[40,41]}$, which account for their frailty but that, in large part, the appropriate response to these conditions is professional support which improves their daily functioning and reduces the rate of deterioration in their health, thus delaying more costly institutionalization ${ }^{[42-44]}$. It was clearly shown in this study how these broader issues of values, philosophy, health and social policy impact on elderly persons and various professionals at the front lines.

Public home care is measured in time and the price is fixed, which leads to reduced flexibility and restricted power to act for the professionals. The focus is geared more towards practical performance than towards personal or social interactions between elderly persons and various professionals ${ }^{[42,45]}$. It seems that all these rules and routines limit freedom, development and spontaneity in the daily work of all groups of professionals, and consequently that these limitations overshadow the primary task, which is to offer individually adapted care and service ${ }^{[45,46]}$. However, freedom and lack of routines or lack of coherent links lead to a vague division of responsibility among the groups of professionals ${ }^{[47,48]}$. This 
meant that some professionals (e.g. taxi drivers) took on more responsibility than they were supposed to and that others, who had the formal competence (e.g. district nurses), were not given the prerequisites to practice their knowledge and make basic observations. The absence of observations for assessing the effects of FD for elderly persons may be seen as a weak point in the FD chain, which can have serious consequences for the elderly people's health due to improper food intake. There needs to be a stronger focus in the budget process on the broader issues, such as values and the philosophy of health and social care policy ${ }^{[4]}$ and other issues that influence the FD process.

\section{Conclusion}

The aim of the study was met, i.e. the professionals' experiences of involvement in FD were explored. By using an action research approach combining participant observation and focus group interviews it was possible to get a comprehensive view over the complex and fragmented FD, which not merely consist of the distribution of a product, i.e. the meal box. It was a limitation that the home help officers were not represented in the study. A disadvantage with the action research approach is that it is time consuming while an advantage is that the professionals get involved in the research process and changes their view from "just looking to actually seeing". The fragmentation in the FD process meant that staff only took responsibility for their part of the chain, and that no one had the full picture of or responsibility for the FD process. However, this fragmentation also led to some professional taking more informal responsibility than they were supposed to or had competence to. Consequently, there is a need for an outline of responsibilities. The findings have implications for nursing, gerontology and in the care for the elderly. Further studies within this area are needed, e.g FD from the elderly persons' perspective, to explore whether their needs are taken into consideration or not.

\section{Acknowledgements}

We are grateful to all the participants for their interesting stories and inspiring dialogues. Thanks to Karin Pettersson and Kristianstad Municipality for welcoming this research.

\section{Contributions}

1) Study design and acquisition of data ZP; 2) Analysis and interpretation of data ZP, LP \& KS; 3) Drafting and critically revising of manuscript ZP, LP, AW \& KS; 4) Have given final approval of the version to be published ZP, LP, AW \& KS.

\section{Source of funding}

The study was supported by Kristianstad University and Skåne County Council. The third author (AW) is supported by the Swedish Research Council and the Skåne County Council's research and development foundation.

\section{Conflict of interests}

No conflicts of interest to declare.

\section{References}

[1] Roy MA, Payette H. Meals-on-wheels improves energy and nutrient intake in a frail free-living elderly population. J Nutr Health Aging. 2006; 10: 554-60. PMid:17183428

[2] Johansson L, Sidenvall B, Malmberg B, Christensson L. Who will become malnourished? A prospective study of factors associated with malnutrition in older persons living at home. J Nutr Health Aging. 2009; 13: 855-61. http://dx.doi.org/10.1007/s12603-009-0242-3

[3] O' Dwyer C, Corish CA, Timonen V. Nutritional status of Irish older people in receipt of meals-on-wheels and the nutritional content of meals provided. J Hum Nutr Diet. 2009; 22: 521-7. PMid:19788707 http://dx.doi.org/10.1111/j.1365-277X.2009.00992.x

[4] Raadu G. Statute handbook for personnel in health and care 2011 (in Swedish: Författningshandbok för personal inom hälso- och sjukvården. 2011). Stockholm: Liber; 2011. 
[5] Social services act. Stockholm: Ministry of health and social affairs, International secretariat. 1981.

[6] Rosen M, Haglund B. From healthy survivors to sick survivors - implications for the twenty-first century. Scand J Public Health. 2005; 33: 151-5. PMid:15823977 http://dx.doi.org/10.1080/14034940510032121

[7] Andersen M, Hedberg A. Food and health fact book from National Food Administration (in Swedish: Mat och hälsa faktabok från Livsmedelsverket). Uppsala: Livsmedelsverket. 2007.

[8] SCB. The Swedish future population 2009-2060 (in Swedish: Sveriges framtida befolkning 2009-2060). Stockholm: Stockholm: Statistical Central Office (in Swedish: Statistiska centralbyrån, SCB). 2009.

[9] Mattsson Sydner Y. The Unempowered Meal - about food and meals in the elderly-care (in Swedish: Den maktlösa måltiden: om mat inom äldreomsorgen). PhD thesis. Uppsala: Institution for home economics (in Swedish: Institutionen för hushållsvetenskap, Univ.). 2002.

[10] Moran MB. Challenges in the meals on wheels program. J Am Diet Assoc. 2004; 104: 1219-21. PMid:15281037 http://dx.doi.org/10.1016/j.jada.2004.04.033

[11] Lirette T, Podovennikoff J, Wismer W, Tondu L. Food preferences and meal satisfaction of Meals on Wheels recipients. Can J Diet Pract Res. 2007; 68: 214-7. PMid:18073004 http://dx.doi.org/10.3148/68.4.2007.214

[12] Krassie J, Smart C. A Review of the nutritional needs of Meals on Wheels consumers and factors associated with the provision of an effective Meal on Wheels service - an Australian perspective. Eur J Clin Nutr. 2000; 54: 275. PMid:10745277 http://dx.doi.org/10.1038/sj.ejcn.1600790

[13] Sneeuw KC, Stam PG, de Graaf C, van Staveren WA. Home food services for the elderly: the consumer and his appreciation of a warm meal service in Arnhem. Tijdschr Gerontol Geriatr. 1991; 22: 29-33. PMid:1877070

[14] Nakura I, Tatara K, Shinsho F, Fukuda H, Nakajima K. Demand by the elderly for "meals-on-wheels" services. Jpn J Publ Health. 1994; 41: 253-61. PMid:817308

[15] Elmér Å. Swedish social politics (in Swedish: Svensk socialpolitik). Lund: Studentlitteratur. 2000.

[16] Petri L. Concept Analysis of Interdisciplinary Collaboration. Wiley Online Library. 2010; 73-82.

[17] Mikkelsen J, Holm HA. Contextual learning to improve health care and patient safety. Educ Health. 2007; 20: 1-9.

[18] Chapman IM. Nutritional disorders in the elderly. Med Clin North Am. 2006; 90:887-907. PMid:16962848 http://dx.doi.org/10.1016/j.mcna.2006.05.010

[19] Cuervo M, Garcia A, Ansorena D, Sanchez-Villegas A, Martinez-Gonzalez M, Astiasaran I, et al. Nutritional assessment interpretation on 22,007 Spanish community-dwelling elders through the Mini Nutritional Assessment test. Public Health Nutr. 2009; 12: 82-90. PMid:18413012 http://dx.doi.org/10.1017/S136898000800195X

[20] Gazzotti C, Arnaud-Battandier F, Parello M, Farine S, Seidel L, Albert A, et al. Prevention of malnutrition in older people during and after hospitalisation: results from a randomised controlled clinical trial. Age Ageing. 2003; 32: 321-5. PMid:12720620 http://dx.doi.org/10.1093/ageing/32.3.321

[21] Stringer ET, Genat WJ. Action research in health. Upper Saddle River, N.J.: Merrill Prentice Hall; 2004.

[22] Larme AC, Meyer JS, Pugh JA. Use of qualitative methods to evaluate diabetes education programs. Diabetes Educ. 1998; 24: 4, 7-8, 499-500.

[23] Meyer J. Evaluating action research. Age Ageing. 2000; 29 Suppl 2: 8-10. PMid:11109939

[24] Morgan DL. Focus groups as qualitative research. Thousand Oaks, Calif. Sage1997.

[25] Kvale S. Doing interviews: Sage. 2007.

[26] Creswell JW. Research design: qualitative, quantitative, and mixed methods approach. Thousand Oaks, Calif.: Sage. 2009.

[27] Reason P, Bradbury H. Handbook of action research: participative inquiry and practice. London: Sage. 2001.

[28] Graneheim UH, Lundman B. Qualitative content analysis in nursing research: concepts, procedures and measures to achieve trustworthiness. Nurse Educ Today. 2004; 24:105-12. PMid:14769454 http://dx.doi.org/10.1016/j.nedt.2003.10.001

[29] Burnard P, Gill P, Stewart K, Treasure E, Chadwick B. Analysing and presenting qualitative data. Br Dent J. 2008 ; $204: 429-32$. PMid:18438371 http://dx.doi.org/10.1038/sj.bdj.2008.292

[30] World Medical Association Declaration of Helsinki - Ethical Principles for Medical Research Involving Human Subjects: http://www.wma.net/en/30publications/10policies/b3/.(18 October 2011, date last accessed)

[31] Dickinson A, Welch C, Ager L. No longer hungry in hospital: improving the hospital mealtime experience for older people through action research. J Clin Nurs. 2008; 1492-502. PMid:18047573 http://dx.doi.org/10.1111/j.1365-2702.2007.02063.x

[32] Gaudreau P, Morais JA, Shatenstein B, Gray-Donald K, Khalil A, Dionne I, et al. Nutrition as a determinant of successful aging: description of the Quebec longitudinal study Nuage and results from cross-sectional pilot studies. Rejuvenation Res. 2007; 10: 377-86. PMid:17708689 http://dx.doi.org/10.1089/rej.2007.0596

[33] Hasselbladh H, Bejerot E, Gustafsson RÅ. Beyond New Public Management: Institutional transformation: in the Swedish Health care Bortom New Public Management: institutionell transformation i svensk sjukvård. Lund: Academia Adacta. 2008. 
[34] Bondas TE. Caritative leadership. Ministering to the patients. Nurs Adm Q. 2003; 27: 249-53. PMid:1367719

[35] Amarantos E, Martinez A, Dwyer J. Nutrition and quality of life in older adults. T J Gerontol A Biol Sci Med Sci. 2001 ; 56 Spec No 2: 54-64. http://dx.doi.org/10.1093/gerona/56.suppl_2.54

[36] Buchanan Dr Fau - Miller FG, Miller Fg Fau - Wallerstein N, Wallerstein N. Ethical issues in community-based participatory research: balancing rigorous research with community participation in community intervention studies. Prog Community Health Partnersh Research. 2007; 1(2): 153-60.

[37] Christensson L, Ek AC, Unosson M. Individually adjusted meals for older people with protein-energy malnutrition: a single-case study. J Clin Nurs. 2001; 10:491-502. PMid:11822497 http://dx.doi.org/10.1046/j.1365-2702.2001.00508.x

[38] Buchanan D, Caldwell R, Meyer J, Storey J, Wainwright C. Leadership transmission: a muddled metaphor? J Health Organ Manag. 2007; 21:246-58. http://dx.doi.org/10.1108/14777260710751726

[39] Wikby K, Ek AC, Christensson L. Nutritional status in elderly people admitted to community residential homes: comparisons between two cohorts. J Nutr Health Aging. 2006; 10: 232-8. PMid:16622585

[40] King G, Farmer J. What older people want: evidence from a study of remote Scottish communities. Rural Remote Health. 2009; 9:1166. PMid:19594291

[41] Wikby K, Fägerskiöld A. The willingness to eat. An investigation of appetite among elderly people. Scand J Caring Sci. 2004; 18: 120-7. PMid:15147474 http://dx.doi.org/10.1111/j.1471-6712.2004.00259.x

[42] Bridges J, Meyer J. Policy on new workforce roles: a discussion paper. Int J Nurs Stud. 2007; 44: 635-44. PMid:17011562 http://dx.doi.org/10.1016/j.ijnurstu.2006.08.008

[43] Esping-Andersen G. The sustainability of welfare states into the twenty-first century. Int J Health Serv. 2000 ; 30 : 1-12. PMid:10707296 http://dx.doi.org/10.2190/H6PN-9R5J-MD9X-P10T

[44] Wikby K, Ek AC, Christensson L. Implementation of a nutritional programme in elderly people admitted to resident homes. Scand J Caring Sci. 2009, Jan 7.

[45] Atwal A, Caldwell K. Do all health and social care professionals interact equally: a study of interactions in multidisciplinary teams in the United Kingdom. Scand J Caring Sci. 2005; 19: 268-73. PMid:16101855 http://dx.doi.org/10.1111/j.1471-6712.2005.00338.x

[46] McCance T, Slater P, McCormack B. Using the caring dimensions inventory as an indicator of person-centred nursing. J Clin Nursing. 2009; 18:409-17. PMid:19191988 http://dx.doi.org/10.1111/j.1365-2702.2008.02466.x

[47] Sydner YM, Fjellstrom C. Food provision and the meal situation in elderly care - outcomes in different social contexts. J Human Nutr Dietet. 2005; 18: 45-52. PMid:15647098 http://dx.doi.org/10.1111/j.1365-277X.2004.00577.x

[48] Mowe M, Bosaeus I, Rasmussen HH, Kondrup J, Unosson M, Irtun O. Nutritional routines and attitudes among doctors and nurses in Scandinavia: a questionnaire based survey. Clinical Nutrition. 2006; 25: 524-32. PMid:16701921

http://dx.doi.org/10.1016/j.clnu.2005.11.011 